\title{
Determination of estrogens in water by HPLC-UV using cloud point extraction
}

\author{
Ling Wang ${ }^{\mathrm{a}, \mathrm{b}}$, Ya-Qi Cai ${ }^{\mathrm{a}}$, Bin $\mathrm{He}^{\mathrm{a}}$, Chun-Gang Yuan ${ }^{\mathrm{a}}$, \\ Da-Zhong Shen ${ }^{b}$, Jing Shao ${ }^{a}$, Gui-Bin Jiang ${ }^{a}$,* \\ a State Key Laboratory of Environmental Chemistry and Ecotoxicology, Research Center for Eco-Environmental Sciences, \\ Chinese Academy of Sciences, P.O. Box 2871, 100085 Beijing, PR China \\ ${ }^{\mathrm{b}}$ School of Chemistry and Chemical Engineering, Shandong University, Jinan 250100, PR China \\ Received 30 October 2005; received in revised form 12 January 2006; accepted 13 January 2006 \\ Available online 17 February 2006
}

\begin{abstract}
A method based on cloud point extraction was developed to determine four kinds of estrogens: estriol (E3), estradiol (E2), estrone (E1), and progesterone $(\mathrm{P})$ in water by high performance liquid chromatography separation and ultraviolet detection (HPLC-UV). The non-ionic surfactant Triton X-114 was chosen as extractant solvent. The parameters affecting extraction efficiency, such as concentrations of Triton X-114 and $\mathrm{Na}_{2} \mathrm{SO}_{4}$, equilibration temperature, equilibration time and centrifugation time were evaluated and optimized. Under the optimum conditions, preconcentration factors of 99 for E3, 73 for E2, 152 for E1 and 86 for P were obtained for $10 \mathrm{~mL}$ water sample. The detection of limitation was $0.23 \mathrm{ng} \mathrm{mL}^{-1}$ for E3, $0.32 \mathrm{ng} \mathrm{mL}^{-1}$ for E2, $0.25 \mathrm{ng} \mathrm{mL}^{-1}$ for E1 and $5.0 \mathrm{ng} \mathrm{mL}^{-1}$ for P. The proposed method was successfully applied to the determination of trace amount of estrogens in wastewater treatment plant (WWTP) effluent water and exposure water with $10 \mathrm{ng} \mathrm{mL}^{-1} \mathrm{E} 2$ for toxicological study in our lab. For the case of WWTP effluent water samples, no estrogen was found. The accuracy of the proposed method was tested by recovery measurements of spiked samples and good recoveries of 81.2-99.5\% were obtained.
\end{abstract}

(C) 2006 Published by Elsevier B.V.

Keywords: Estrogens; Cloud point extraction; Triton X-114; Non-ionic surfactant; HPLC-UV

\section{Introduction}

The detection of natural and synthetic estrogens in water $[1,2]$ has attracted great interest in the research community and the general public because of their potential adverse ecological effects. Exposure to environmental estrogens has given rise to decreased sperm counts, increased testicular, prostate, breast cancer, and to reproductive disorders in human males [3]. Relatively large amounts of natural and synthetic reproductive hormones enter various environments via several pathways such as the sewage treatment plant (STP) effluent outfalls. The large amounts of animal wastes and biosolids applied to agricultural fields might flow into nearby bodies of water or infiltrate through the soil into groundwater [4]. Cattle and poultry manure have been reported as a source of the environmental loadings of $17 \beta$ estradiol [1].

\footnotetext{
* Corresponding author. Tel.: +86 106284 9334; fax: +86 1062849179

E-mail address: gbjiang@mail.rcees.ac.cn (G.-B. Jiang).
}

Naturally occurring estrogens include estradiol and its most common metabolites and/or precursors: estrone and/or estriol. Progesterone is considered as a hormone balancer. Their physicochemical properties were listed in Table 1.The concentrations of estrogens in the environment are about several sub-ng to thousands of $\mathrm{n} \mathrm{L} \mathrm{L}^{-1}$ level $[4,5]$. The most widely used methods for analyzing these estrogens are chromatographic techniques such as gas chromatography (GC) or high performance liquid chromatography (HPLC), but their sensitivity and selectivity limit their direct use for determination of these contaminants at a very low concentration level in environmental samples with complex matrix. Therefore, a sample pretreatment step prior to chromatographic analysis is usually necessary, such as liquid-liquid extraction (LLE) and solid-phase extraction (SPE). Unfortunately, all of these methods require a large sample volume and time-consuming. In particular, the traditional liquid-liquid extraction method is also dangerous to analysts because of the large volume of volatile organic solvent required. So in the last decades, the green liquid-liquid extraction method cloud point extraction (CPE) has been employed in analytical chemistry to 
Table 1

Physicochemical properties of estrogens ${ }^{\mathrm{a}}$

\begin{tabular}{|c|c|c|c|c|}
\hline Chemical name & Molecular weight & Water solubility $\left(\mathrm{mg} / \mathrm{L}, 25^{\circ} \mathrm{C}\right)$ & Vapour pressure (mmHg) & $\log K_{\text {ow }}$ \\
\hline Estrone (E1) & 270.4 & 30 & $1.4 \times 10^{-7}$ & 3.13 \\
\hline $17 \beta$-Estradiol (E2) & 272.4 & $3.6^{\mathrm{b}}$ & $1.3 \times 10^{-8}$ & 4.01 \\
\hline Estriol (E3) & 288.4 & 441 & $1.97 \times 10^{-10}$ & 2.45 \\
\hline Progesterone (P) & 314.4 & 8.81 & $1.3 \times 10^{-6}$ & 3.87 \\
\hline
\end{tabular}

a Data from SRC PhysProp Database.

b Tested at $27^{\circ} \mathrm{C}$.

preconcentrate organic compounds [6-8] and metal ions [9-11]. Compared with the traditional organic liquid-liquid extraction, cloud point extraction requires a very small amount of relatively nonflammable and nonvolatile surfactants that are friendly to the environment. Another important merit is that no analytes are lost because it is unnecessary to evaporate the solvents. Using appropriate conditions such as temperature, concentration of surfactant, and equilibration time, the solution containing the surfactant becomes turbid and separates two phases: a surfactantrich phase (at a very small volume) and a larger volume of aqueous solution phase (bulk amount) with a diluted surfactant concentration, which approximates to its critical micelle concentration (CMC). The hydrophobic analytes of the solution are extracted into the surfactant-rich phase. Compared to the initial solution volume, the surfactant-rich phase volume is very small, thus a high enrichment factor can be obtained. As a promising alternative to traditional solvent extraction, CPE, especially the extraction of environmental pollutants is still at its initial stage. Only a few reports can be found on the extraction of polycyclic aromatic hydrocarbons (PAH) [12-14] and polychlorinated biphenyls (PCBs) [15] and dibenzofurans (PCDFs) [16], polychlorinated dibenzop-dioxins (PCDDs) [14], pesticides [16], vitamins [17] and other organic compounds such as chlorinated phenols [18]. All these indicate that cloud point extraction have great analytical potential as an effective enrichment method. But no reports have been published about how to extract estrogens from the water.

In the present study, a method was developed for analyzing the trace level determination of estrogens in water by CPE using Triton X-114 as the extraction solvent. The instrument is a high performance liquid chromatography coupled with an UV detector.

\section{Experimental}

\subsection{Reagents}

All reagents used were HPLC grade, and purified water from a Milli Q system was used throughout the experiments. Estroil, $17 \beta$-estradiol, estrone and progesterone were obtained from Sigma-Aldrich, USA. Standard stock solutions $(1000 \mu \mathrm{g} / \mathrm{mL})$ containing these compounds were prepared by dissolving an appropriate amount of these compounds in methanol. Working solutions were prepared daily by an appropriate dilution of the stock solutions. The non-ionic surfactant TritonX-114 (Acros Organics, New Jersey, USA) was used without further purification. $\mathrm{Na}_{2} \mathrm{SO}_{4}$ (Beijing Chemical Factory, PR China) was prepared immediately before each experiment.

The vessels used for trace analysis were washed with methanol and purified water before usage.

\subsection{Instrumentation}

The HPLC system used includes an Agilent 1100 series binary pump, an Agilent 1100 series VWD detector and a Rheodyne $7225 \mathrm{i}$ injector. The separations were performed on an Inertsil ODS-C18 column $(250 \mathrm{~mm} \times 4.6 \mathrm{~mm}$, particle size, $5 \mu \mathrm{m})$. Acetonitrile and water were used as mobile phase with the gradient program as follows: $0-4.5 \mathrm{~min}, 45: 55 ; 5.0-20 \mathrm{~min}$ 75:25, acetonitrile:water, $\mathrm{v} / \mathrm{v}$, and $1 \mathrm{~mL} \mathrm{~min}^{-1}$ was selected as the flow rate of the mobile phase. The VWD detector settings were as follows, 0-10 min, $200 \mathrm{~nm}$, for E3, E2, E1, 11-20 min, and $240 \mathrm{~nm}$ for progesterone. A personal computer equipped with an Agilent Chemstation program for LC systems was used to acquire and process chromatographic data. Peak area was used as the analytical measurement. A thermostatic bath (TB85 Therma Bath, Shimadsu, Japan), maintained at the desired temperature, was used to obtain cloud point preconcentration. Centrifugation with calibrated centrifugal tubes (Beijing Medicinal Instrument company, PR China) was used to accelerate the phase separation process. Easypure deionized water was used in this study (Model D7382-33, Barnstead Thermolyne Corporation, Dubuque, IA, USA). An Agilent syringe was used for injecting the sample into the loop. Twenty microliters were chosen as the injecting volume.

\subsection{Cloud point procedure}

For the extraction and preconcentration of estrogens, an aliquot of $10 \mathrm{~mL}$ of sample solution containing the analytes with $0.25 \%\left(\mathrm{w} / \mathrm{v}\right.$ ) of TritonX-114 and $0.4 \mathrm{M} \mathrm{Na}_{2} \mathrm{SO}_{4}$, were kept for $60 \mathrm{~min}$ in the thermostatic bath at $45^{\circ} \mathrm{C}$. Then the phase separation was accelerated by centrifugation for $5 \mathrm{~min}$ at $3500 \mathrm{rpm}$. After phase separation, the bulk aqueous phase was removed and the volume of the two phases was measured. Then, $20 \mu \mathrm{L}$ of the remaining surfactant-rich phase was directly injected in the HPLC loop for subsequent analysis.

\subsection{Extraction of estrogens in real samples}

Sample 1: Fishes were kept in the exposure water with $10 \mathrm{ng} \mathrm{mL}{ }^{-1} \mathrm{E} 2$ for toxicological study in our lab. Theoretically, 
E2 may degrade into E1 and $\mathrm{CO}_{2}$ in short time. This exposure water was determined after $24 \mathrm{~h}$.

Sample 2: The effluent water from Gaobeidian (waste water treatment factory) WWTP (Beijing, China).

The real water samples were filtered through a $0.45 \mu \mathrm{m}$ poresize membrane filter to remove the suspended particular matter and detected within $48 \mathrm{~h}$ after receiving them from WWTP (protected by adding $1 \%$ formaldehyde to the water). A $10 \mathrm{~mL}$ real water sample was submitted to the cloud point extraction procedure using $0.25 \%$ TritonX-114 and $0.4 \mathrm{M} \mathrm{Na}_{2} \mathrm{SO}_{4}$. After phase separation, $20 \mu \mathrm{L}$ of surfactant-rich phase was directly injected to the injection loop for the analysis. Standard solutions containing $10,10,10,50 \mathrm{ng} \mathrm{mL}^{-1}$ of E3, E2, E1 and P were added to a $10 \mathrm{~mL}$ real water for the recovery test, respectively.

\section{Results and discussion}

TritonX-114 with a cloud point temperature of 23 or $24{ }^{\circ} \mathrm{C}$ $[19,20]$ is one of the most commonly used non-ionic surfactants in the cloud point extraction [20]. There are several different parameters that can influence the extraction efficiency. They were investigated in our experiments. However, it is found that the preconcentration factor is independent of the initial concentration [21].

\subsection{Effect of the concentration of surfactant}

The theoretical preconcentration factor depends on the concentration of surfactant. For its low cloud point temperature and high density, Triton X-114 was chosen as the extractant solvent, and phase separation was facilitated by centrifugation [22]. The effect of the concentration of surfactant was examined in our study and the result was shown in Fig. 1. From Fig. 1, it can be found that when the concentration of surfactant in solution varies in the range $0.20-2.0 \%$, the highest extraction efficiency is at $0.25 \%$. In this experiment, when the concentration of surfactant is below $0.25 \%$, it always suspends in the bulk solution and is

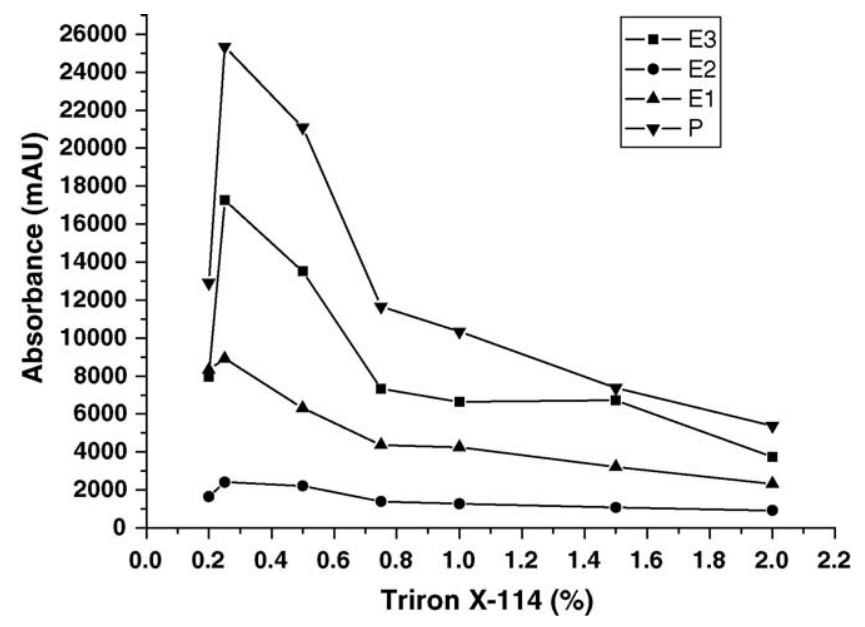

Fig. 1. Extraction effect of the estrogens as a function of Triton X-114 concentration: ( $\mathbf{\square})$ estriol; ( $(\checkmark)$ estradiol; $(\boldsymbol{\Lambda})$ estrone; $(\boldsymbol{\nabla})$ progesterone. very difficult to separate into two phases. Based on these experiment results, $0.25 \%$ TritonX-114 was adopted as the optimum amount to achieve best analytical signals and highest extraction efficiency.

\subsection{Effect of equilibration time}

The equilibration time can affect the preconcentration factor of the surfactant [15], therefore, study on the determination of the optimum equilibration time was carried out to obtain appropriate recovery percentages for the analytes. Triton X-114 surfactant exhibits a similar behavior for all the estrogens under the given concentration range. Fig. 2 shows an increase in the extraction efficiency within the initial $20 \mathrm{~min}$, then slight decrease in the following $30 \mathrm{~min}$ and increase again at $60 \mathrm{~min}$, which is similar to the result of other research [20]. As a consequence, $60 \mathrm{~min}$ was adopted as the optimum equilibration time.

\subsection{Effect of concentration of $\mathrm{Na}_{2} \mathrm{SO}_{4}$}

The addition of salt to the solution can influence the extraction process. For most non-ionic surfactant, the presence of salts may facilitate phase separation since they increases the density of the aqueous phase [23]. Available electrolytes can also change the cloud point temperatures of non-ionic surfactant. The relevant electrolytes are usually in high concentrations (exceeding $0.1 \mathrm{M})$ [24]. The salting-in and salting-out effects can be used to interpret the electrolyte effects on the cloud points of non-ionic surfactant [25]. To study the influence of the electrolyte, different concentrations of $\mathrm{Na}_{2} \mathrm{SO}_{4}$, ranging from 0 to $0.7 \mathrm{M}$ were added to the solution. The results are in concordance with other studies. The final surfactant-rich phase volume was not noticeably influenced by the increased ionic strength [25]. When the concentration is higher than $0.4 \mathrm{M}$, the surfactant-rich phase will be on the surface of the solution, which will make it more difficult to separate the extraction solvent into two phases and the accuracy and reproducibility probably were not satisfactory. As

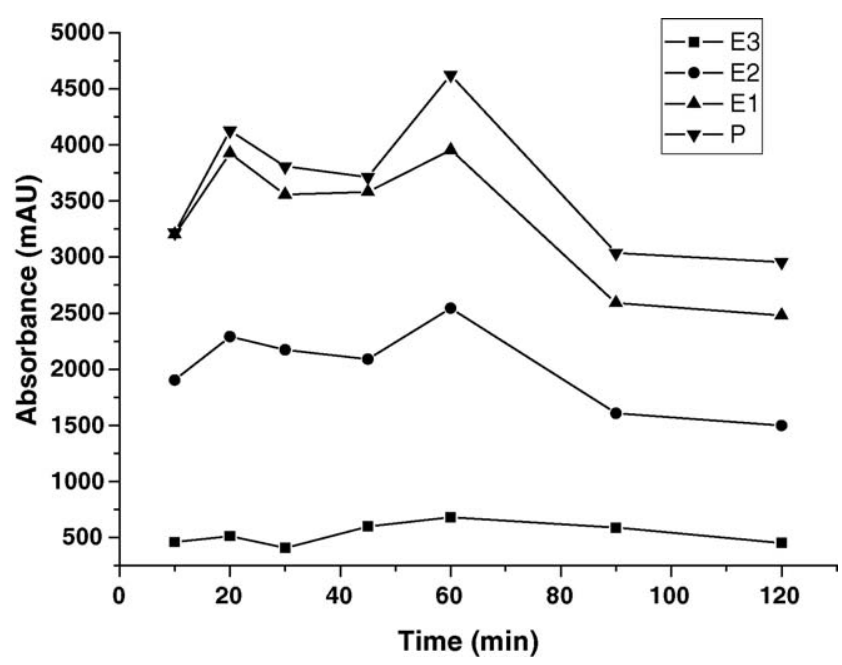

Fig. 2. Effect of the equilibration time on the extraction efficiency: (ם) estriol; ( $)$ estradiol; ( $\boldsymbol{\Delta})$ estrone; $(\boldsymbol{\nabla})$ progesterone. 


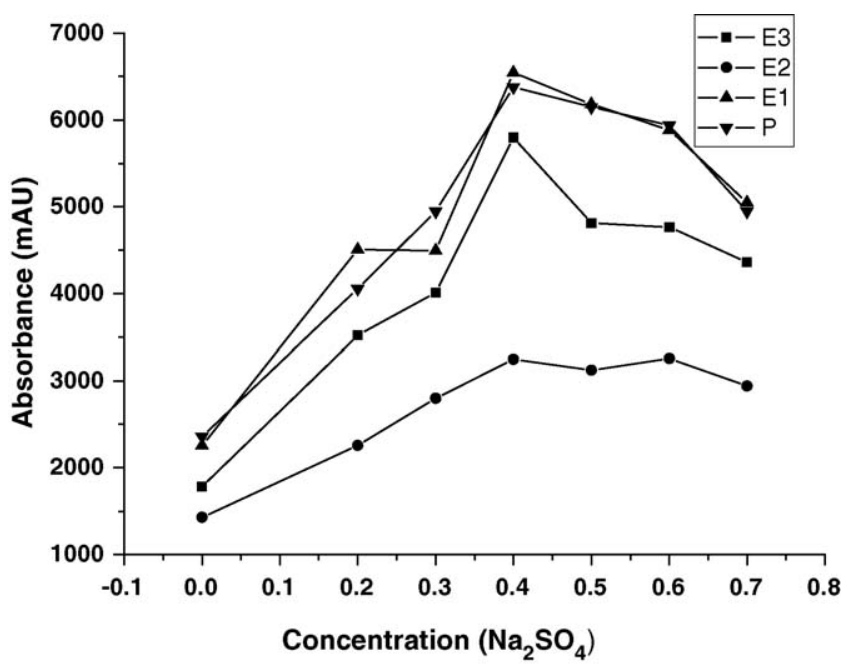

Fig. 3. Effect of the ionic strength on the extraction efficiency: ( $\boldsymbol{\square})$ estriol; estradiol; $(\boldsymbol{\Delta})$ estrone; $(\boldsymbol{\nabla})$ progesterone.

shown in Fig. 3, the extraction effect is best when the concentration is $0.4 \mathrm{M}$.

\subsection{Effect of the equilibration temperature}

When the cloud point extraction procedure was processed at equilibration temperature of the surfactant, the best extraction effect was achieved [26]. Thus, it is necessary to examine the effect of temperature on cloud point extraction. If the temperature is lower than the cloud point, two phases cannot be formed. Higher temperature leads to the decomposition of estrogens. In order to employ the lowest possible equilibration temperature to the efficient separation of phases, the equilibration temperature was examined. Theoretically, the optimal equilibration temperature of the extraction occurs when the equilibration temperature is $15-20{ }^{\circ} \mathrm{C}$ greater than the cloud point temperature of surfactant [26]. Fig. 4 shows the effects of equilibration temperature on the extraction efficiency. The maximum signals were obtained at

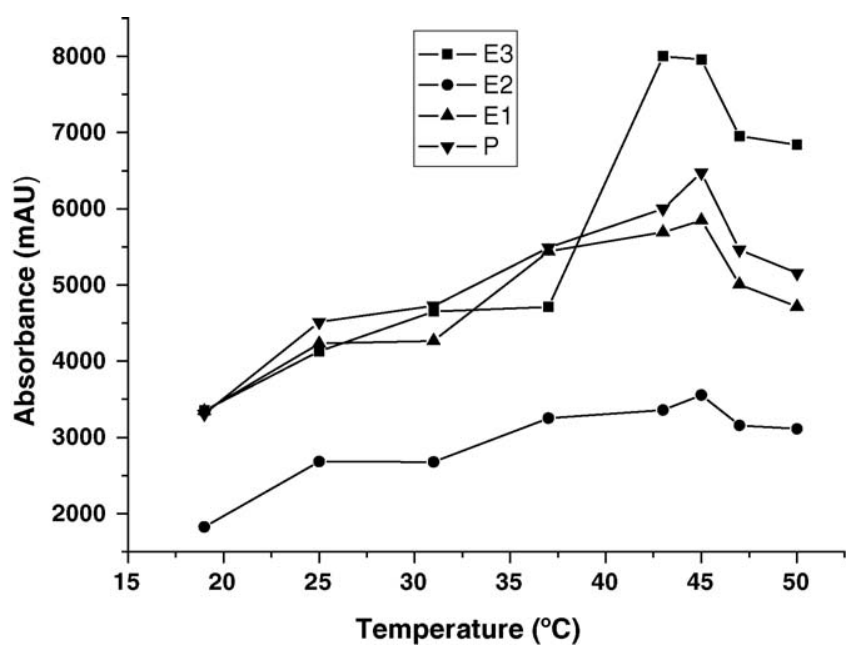

Fig. 4. Effect of temperature on the extraction efficiency: (ם) estriol; ( $\mathbf{\square})$ estradiol; $(\boldsymbol{\Delta})$ estrone; $(\boldsymbol{\nabla})$ progesterone.
Table 2

Analytical characteristics of the method

\begin{tabular}{lllclc}
\hline Analyte & $\begin{array}{l}\text { Enrichment } \\
\text { factor }\end{array}$ & $\begin{array}{l}\text { Detection } \\
\text { limit }^{\mathrm{a}} \\
\left(\mathrm{ng} \mathrm{mL}^{-1}\right)\end{array}$ & R.S.D. (\%) & $R^{2}$ & $\begin{array}{l}\text { Linear range } \\
\left(\mathrm{ng} \mathrm{mL} \mathrm{m}^{-1}\right)\end{array}$ \\
\hline Estriol & 99 & 0.23 & 8.5 & 0.9973 & $1-51.6$ \\
Estradiol & 73 & 0.32 & 12 & 0.996 & $1-90$ \\
Estrone & 152 & 0.25 & 8.1 & 0.9961 & $1-192$ \\
Progesterone & 86 & 5.0 & 10.1 & 0.9994 & $50-1600$ \\
\hline
\end{tabular}

${ }^{\text {a }}$ Limit of detection defined as three times the signal-to-noise ratio.

temperatures between $37-50{ }^{\circ} \mathrm{C}$. Therefore $45^{\circ} \mathrm{C}$ was selected as the working equilibration temperature.

\subsection{Effect of centrifugation time}

The effect of centrifugation time on phase separation was studied in the range $2-20 \mathrm{~min}$ at $3500 \mathrm{rpm}$. The results showed that 5 min was enough to get a complete phase separation. So a centrifugation time of $5 \mathrm{~min}$ was selected as optimum.

\subsection{Characteristics of analytical method}

Table 2 shows some characteristics of the proposed method. The linearity of the four estrogen compounds was in the range $1.0-51.6 \mathrm{ng} \mathrm{mL}^{-1}$ for E3, 1-90 $\mathrm{ng} \mathrm{mL}^{-1}$ for E2, 1-192 $\mathrm{ng} \mathrm{mL}^{-1}$ for $\mathrm{E} 1$ and $50-1600 \mathrm{ng} \mathrm{mL}^{-1}$ for $\mathrm{P}$, respectively. The detection limits based on three levels of the background signal to noise were $0.23 \mathrm{ng} \mathrm{mL}^{-1}$ for $\mathrm{E} 3,0.32 \mathrm{ng} \mathrm{mL}^{-1}$ for $\mathrm{E} 2$, $0.25 \mathrm{ng} \mathrm{mL}^{-1}$ for $\mathrm{E} 1$ and $5 \mathrm{ng} \mathrm{mL}^{-1}$ for P, respectively. Fig. 5 is the comparison of chromatograms before enrichment and after enrichment.

\subsection{Analysis of real samples}

In order to validate the accuracy and precision of the proposed method under the selected conditions, WWTP effluent water sample, exposure water in our lab and spiked samples

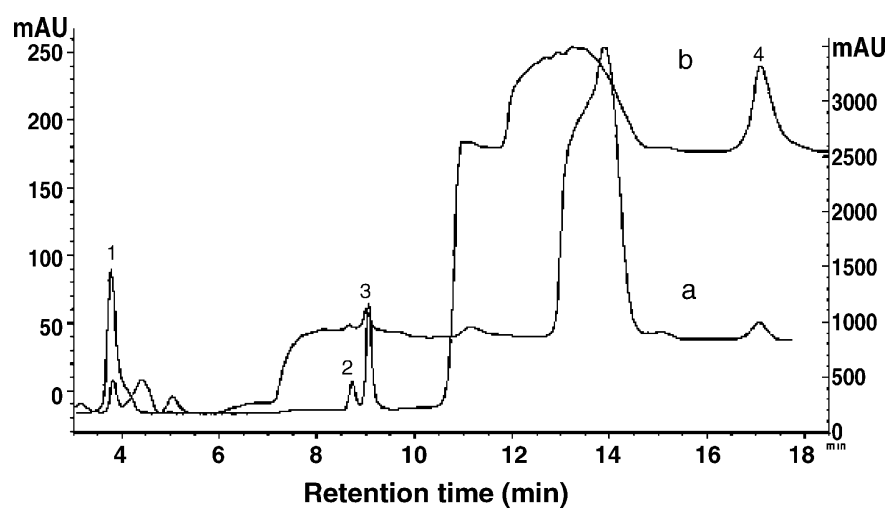

Fig. 5. Chromatograph of a standard solution (a) standard solution in the bulk aqueous before enrichment (left). (b) Standard solution in the enrichment-phase (right). Experimental conditions: Triton $\mathrm{X}-114$ is $0.25 \%$ and $0.4 \mathrm{M}$ for $\mathrm{Na}_{2} \mathrm{SO}_{4}$, equilibration temperature is $45^{\circ} \mathrm{C}$, equilibration time is $60 \mathrm{~min}$. 
Table 3

Determination and recoveries of four analytes spiked water samples

\begin{tabular}{cccc}
\hline Water sample & Added $\left(\mathrm{ng} \mathrm{mL}^{-1}\right)$ & Found $^{\mathrm{a}}\left(\mathrm{ng} \mathrm{mL}^{-1}\right)$ & Recovery $^{\mathrm{b}}(\%)$ \\
\hline WWTP effluent & water & & \\
E3 & - & nd & - \\
& 10.0 & 9.9 & $99.0 \pm 8.5$ \\
E2 & - & nd & - \\
& 10.0 & 8.1 & $81.2 \pm 11.5$ \\
E1 & - & nd & - \\
& 10.0 & 9.8 & $98.0 \pm 8.1$ \\
P & - & nd & - \\
& 50.0 & 46.1 & $92.1 \pm 10.1$ \\
Exposured water in our lab (E2: $10 \mathrm{ng}$ & $\mathrm{mL}-1)$ & \\
E3 & - & nd & \\
& 10.0 & 9.9 & $99.5 \pm 10.1$ \\
E2 & - & 5.6 & - \\
& 10.0 & 15.4 & $99.0 \pm 12.0$ \\
E1 & - & nd & \\
& 10.0 & 9.8 & $99.0 \pm 10.5$ \\
P & - & nd &
\end{tabular}

${ }^{\mathrm{a}}$ Mean for three determinations.

${ }^{\mathrm{b}}$ Mean and standard deviation for three determinations. nd: not detected.

had been tested. The results are shown in Table 3. In all cases the spiked recoveries were satisfied, showing no obvious matrix interferences.

\section{Conclusion}

The cloud point technique was applied as an effective method for the extraction of four kinds of estrogens (estriol, estradiol, estrone, progesterone) in aqueous samples. Using HPLC technique coupled with UV detector, the concentration of Triton $\mathrm{X}-114$ is $0.25 \%$ and $0.4 \mathrm{M}$ for $\mathrm{Na}_{2} \mathrm{SO}_{4}$, equilibration temperature is $45^{\circ} \mathrm{C}$, equilibration time is $60 \mathrm{~min}$ and centrifugation time is $5 \mathrm{~min}$. The high recoveries and precision showed the optimal experimental condition were satisfied. In conclusion, the proposed method is a simple, rapid, and effective method for the simultaneous determination of four kinds of estrogens with their very low concentration in environmental water.

\section{Acknowledgements}

This work was jointly supported by the National Basic Research Program of China (2003CB415001) and National Natural Science Foundation of China (20137010).

\section{References}

[1] D. Kolpin, E. Furlong, M. Meyer, E.M. Thurman, S. Zaugg, L. Barber, H. Buxton, Environ. Sci. Technol. 36 (2002) 1202.

[2] M.J. López de Alda, D. Barceló, J. Chromatogr. A 892 (2000) 391.

[3] R. Liu, J.L. Zhou, A. Wilding, J. Chromatogr. A 1022 (2004) 179-189.

[4] M.J. López de Alda, D. Barceló, Fresenius J. Anal. Chem. 371 (2001) 437.

[5] W. Roger, Giese, J. Chromatogr. A 1000 (2003) 401.

[6] S.Y. Yuan, C. Liu, C.S. Liao, B.V. Chang, Chemosphere 49 (2002) 1295.

[7] I. Casero, D. Sicilia, S. Rubio, D. Pérez-Bendito, Anal. Chem. 71 (1999) 4519.

[8] R. Carabias-Martínex, E. Rodríguez-Gonzalo, J. Domínguez-Alvarez, J. Hernández-Méndez, Anal. Chem. 71 (1999) 2468.

[9] J.R. Chen, K.C. Teo, Anal. Chim. Acta 434 (2001) 325.

[10] J.L. Manzoori, G. Karim-Nezhad, Anal. Chim. Acta 484 (2003) 155.

[11] Ch.G. Yuan, G.B. Jiang, Y.Q. Cai, B. He, J.F. Liu, Atom. Spectrom. 25 (2004) 170.

[12] A. Rodenbrock, K. Selber, M.R. Egmond, M.R. Kula, Bioseparation 9 (2000) 269.

[13] A. Collén, J. Persson, M. Linder, T. Nakari-Setălă, M. Penttilä, F. Tjerneld, U. Sivars, Biochim. Biophys. Acta 1569 (2002) 139.

[14] S.R. Sirimanne, J.R. Barr, D.G. Patterson, L. Ma, Anal. Chem. 68 (1996) 1556.

[15] A. Eiguren-Fernández, Z. Sosa-Ferrera, J.J. Santana-Rodríguez, Anal. Chim. Acta 358 (1998) 145.

[16] A. Eiguren-Fernández, Z. Sosa-Ferrera, J.J. Santana-Rodríguez, Analyst 124 (1999) 487

[17] C. García-Pinto, J.L. Pérez-Pavón, B. Moreno-cordero, Anal. Chem. 64 (1992) 2334.

[18] T. Saitoh, W.L. Hinze, Anal. Chem. 63 (1991) 2520

[19] K. Toerne, R. Rogers, R.V. Wandruszka, Langmuir 16 (2000) 2141.

[20] B. Delgado, V. Pino, J.H. Ayala, V. González, A.M. Afonso, Anal. Chim. Acta 518 (2004) 165.

[21] J.L. Li, B.H. Chen, J. Colloid Interf. Sci. 263 (2003) 625.

[22] F. Shemirani, M. Baghdadi, M. Ramezani, M.R. Jamali, Anal. Chim. Acta 534 (2005) 163.

[23] R. Carabias-Martýnez, E. Rodrýguez-Gonzalo, B. Moreno-Cordero, J.L. Rez-Pavon, C. Garcýa-Pinto, E. Fernandez Laespada, J. Chromatogr. A 902 (2000) 251.

[24] M.K. Purkait, S.S. Vijay, S. DasGupta, S. De, Dyes and Pigments 63 (2004) 151.

[25] V. Pino, J.H. Ayala, A.M. Afonso, V. González, J. Chromatogr. A 949 (2002) 291.

[26] R.P. Frankewich, W.L. Hinze, Anal. Chem. 66 (1994) 944. 